
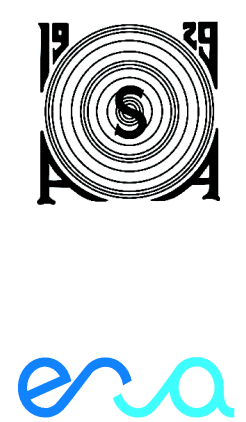

\title{
Assessment of Acoustical Characteristics for Historical Baths (Hammams)
}

\author{
A. Aydin, A. Tavukcuoglu and M. Caliskan
}

Middle East Technical University, Dept of Architecture, METU (ODTU), Inonu Blvd, 06531 Ankara, Turkey

caliskan@metu.edu.tr 
Comprehensive studies are necessary to better understand the original acoustical characteristics of historical baths (hamams) in order to discover the historical technologies establishing good acoustical performance in these structures and keep their proper functioning for long periods of time. The study was conducted on Sengul Hamam, a historical Turkish bath dated to $15^{\text {th }}$ century, belonging to the Ottoman period. Its acoustical characteristics were examined by using 3D computer modelling and acoustical simulation methods supported by laboratory analyses. The joint interpretation of the results was done in order to assess the original acoustical features of historical Turkish baths and acoustical failures related to unconscious recent repairs.

\section{Introduction}

The architectural and technological features of the historical Turkish baths (hamams) should be well-understood in order to discover their historical technologies establishing good acoustical performance and also to keep their functioning for long periods of time. The number of studies on the analyses of original acoustical properties of historical structures considering acousto-physical properties of historical materials remain, however, rather limited. Comprehensive studies are, therefore, needed, in this regard.

This study was focused on the assessment of original acoustical features for historical baths with an emphasis on microclimatic conditions particular for bath structures, such as very hot and wet air, and sound absorption characteristics of historical materials. For this purpose, Sengul Hamam which is a $15^{\text {th }}$ century Turkish bath, still representing the continuous experience of Turkish bath culture in Anatolia, was examined by 3D computer modelling and acoustics simulation method. The analyses of acoustics simulation were based on two cases: The first one was the analysis of $A S-I S$ case representing the present conditions of the interiors after the structure was repaired with contemporary cement-based materials. The second one was ORIGINAL case based on an assumption that the interiors were repaired with materials compatible with historical ones. These two cases were evaluated and compared with each other in terms of basic acoustical parameters, such as, reverberation time, early decay time, clarity, lateral fraction, sound transmission index.

\section{Materials and Methods}

The Sengul Hamam is a typical double bath consisting of two separate parts for men and women. The volume of women's section is $714 \mathrm{~m}^{3}$ while the volume of men's section is $508 \mathrm{~m}^{3}$. Each bath is composed of basically three sections: Undressing room, Tepidarium and Caldarium. The tepidarium and caldarium sections are used for bathing purposes. An elevated marble platform, "göbektaşı", located at the centre of the caldarium, which is the hottest surface of the hammam. There are also stone basins (kurna) in which hot and cold water were mixed to achieve a desired temperature of water for bathing.

The structure was constructed with stone masonry walls with brick transitions and brick upper structure. The interior of the structure has been recently-repaired. The floors of the structure and the lower parts of walls were covered with marble tiles while the remaining wall and dome surfaces were covered with oil painted cement-based plaster.

In historical Turkish baths, persons, having a bath around basins and on the elevated marble platform, speak with each other and sing songs in allegro rhythms, sometimes accompanied by percussion instruments, such as by tabor. By this study, the speech and musical performances of an historical Turkish bath, Sengul Hamam, were, discovered and then the success of historical acoustical features was discussed.

The acoustic performance of Sengul hamam's interiors was examined both for the women's part and the men's part in order to discover its original acoustical features and to assess the present situation by taking into consideration the recent incompatible repairs. The $A S-I S$ case and the ORIGINAL case were examined in terms of basic acoustical parameters, such as, reverberation time $(R T)$, early decay time $(E D T)$, lateral fraction $(L F 80)$, speech transmission index $(S T I)$, clarity $(C 80)$ [1]. The analyses were done by 3D computer modeling and acoustics simulation method. Supportive laboratory measurements were performed to determine the sound absorption properties of the historical plasters used in historical Turkish baths .The procedures of the analyses were briefly explained below:

\subsection{Acoustical simulation}

The study was carried to define the acoustical characteristics of the caldarium and tepidarium sections of women's and men's parts. Their audial performance was evaluated by taking into consideration of the volume, materials use, environmental conditions and positioning of sound source and receiver. The models of two cases representing the $A S-I S$ and ORIGINAL conditions were produced for the analyses of virtual acoustical environment. Both for the $A S$-IS and ORIGINAL cases, the floors and the lower parts of walls were marble-clad and dome lights were made of $3 \mathrm{~mm}$-thick glass. All wall and dome surfaces remained were assumed to be covered with cement-based plasters with oil paint for the $A S-I S$ case, while those surfaces were thought to be repaired with lime-based plasters compatible with historical ones for the ORIGINAL case. The models were examined for constant microclimatic conditions of $40^{\circ} \mathrm{C}$ and $100 \% \mathrm{RH}$. The sound absorption coefficient data for marble, glass and oil painted cementbased plaster, required for the acoustical modelling, were taken from the literature $[2,3]$ while the empirical data obtained in this study for the damp historical lime plasters was used in the acoustical modelling of ORIGINAL case. 
During the modelling, a special care was also given to the geometric forms of spaces, such as domes, vaults, arches. The 3D computer modelling of the structure was done by AutoCAD 2007. The analyses of 3D acoustical simulation were done by using ODEON combined 8.5 software and based on the acceptation that the sound source was located at the center of caldarium, on the elevated marble platform, while the point receiver was $6 \mathrm{~m}$ away from the source (Fig.1). The examination was done for the unoccupied situation of the structure.
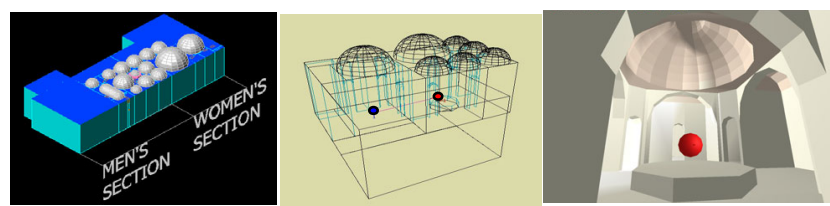

Fig.1. The axonometric view of Sengul hamam (on the left); the ODEON 3D computer model of its women's section (in the middle); ODEON wire-frame model of the section showing the locations of sound source (red dot) on the elevated platform of caldarium and of receiver (blue dot) $6 \mathrm{~m}$ far away from the source (on the right).

The verification of the surfaces whether they were completely watertight or not, was checked by the ray tracing method. The mean of the reverberation time for the receiver position was calculated as the "Global estimate reverberation time". The perception of sound by a person sitting at any place in the caldarium space was simulated by using the by the "Grid response" calculation method and the results were mapped in terms of all acoustical parameters mentioned above. The data was processed for the octave bands of $63,125,250,500,1000,2000,4000$ and $8000 \mathrm{~Hz}$ (1/1 octave bands), however, the emphasis was given to the mid frequency region ,i.e., $500 \mathrm{~Hz}$ and $1000 \mathrm{~Hz}$ sound frequencies which are considered to characterize acoustical properties of spaces [2-4].

\subsection{Laboratory analyses}

The relationship between the sound absorption coefficient of historical plasters and their moisture content was investigated by means of laboratory analyses. The laboratory analyses were conducted on historical lime plaster samples collected from Amasya Hizir Pasa Hamam, belonging to the same period of Sengul Hamam. The samples consisted of 3 plaster layers with $3.5 \mathrm{~cm}$-thick in total and each having similar physical properties, such as the mean value of $1.27 \mathrm{~g} / \mathrm{cm} 3$ as bulk density and of $52 \%$ as effective porosity. Since the interior of the structure is very humid, the materials should be in equilibrium in such wet conditions. Therefore, the sound absorption coefficient values $(\alpha)$ were examined both for dry $\left(\alpha_{d}\right)$, damp $\left(\alpha_{85}\right)$ and wet $\left(\alpha_{100}\right)$ conditions. When the sample was achieved to a constant mass at $85 \% \mathrm{RH}$, it assumed to be damp with an equilibrium moisture content of $4 \%$ by weight. This is a reliable situation for the calculations of $\alpha$ value for a completely damp porous material. When the sample was left at $100 \% \mathrm{RH}$, it assumed to be almost wet with an equilibrium moisture content of $7.4 \%$ by weight. However, this is not a reliable situation since the pores in the material were partially filled with water. The $\alpha_{85}$ value of historical plasters, therefore, represents the real sound absorption characteristics of historical plaster. The sound absorption coefficients were determined by Standing Wave Method using an impedance tube. Measurements were carried on circular-cut dry, damp and wet samples of $70 \mathrm{~mm}$ diameter in the frequency range from $100 \mathrm{~Hz}$ to $2 \mathrm{kHz}$.

\section{Results and Discussion}

The results were interpreted together in order to evaluate the sound absorption characteristics of finishing materials used in an historical Turkish bath, to define its original acoustical features and to asses the affects of recent incompatible repairs to its original acoustical features.

\subsection{Sound absorption characteristics of historical plasters used in historical Turkish baths}

The results of the laboratory analysis were summarized in Fig. 2 and Table 1. The experimental data obtained according to the frequencies of $1 / 3$ octave bands were given in Table 1 , both for the dry and damp historical lime plasters. In the range of mid-frequency (between 500 and $1000 \mathrm{~Hz}$ ), the $\alpha_{d}$ and the $\alpha_{85}$ of the historical plaster layers were determined to be in the range of 0.20 to 0.29 with a mean value of 0.25 and 0.15 and 0.29 with a mean value of 0.21 , respectively (Table 1). Except for the $500 \mathrm{~Hz}$ frequency band, the dry and damp samples were observed to have similar sound absorption characteristics. The $\alpha_{100}$ of the historical plaster layers, however, was lower than those of dry and damp samples, being in the range of 0.08 to 0.18 with a mean value of 0.13 .

Those results were compared with the other finishing materials used in Sengul Hamam, as shown in Fig.2, by using the data in the frequency of $1 / 1$ octave bands. The $\alpha$ of historical lime plaster layers in dry, damp and wet conditions, was found to be considerably higher than those of oil-painted cement-based plaster, marble and glass surfaces. Considering the real moisture content situation of the historical plasters for the ORIGINAL case, the historical sample, with the $\alpha_{85}$ value of 0.21 , exhibited almost 7 times greater sound absorptive capacity than the cement-based one, having an average $\alpha$ of 0.03 in the range of midfrequencies $[2,3,5]$.

Historical Frequency, $\mathrm{Hz}$

Lime 10012516020025

Plaster 1001251602002503154005006308001000125016002000

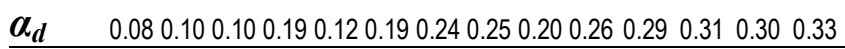

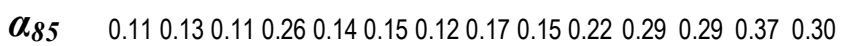

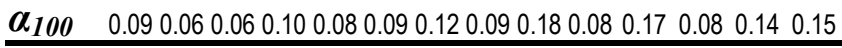

Table 1 The sound absorption coefficient values for the dry $\left(\alpha_{d}\right)$, damp $\left(\alpha_{85}\right)$ and wet $\left(\alpha_{100}\right)$ historical lime plaster versus the frequency of $1 / 3$ octave bands.

It is well known that cement-based materials are incompatible with the historical materials since they introduce dampness and soluble salts problem to the historical structures [6-8]. By this study, it was also confirmed that the contemporary cement-based plaster was incompatible with the porous historical lime plasters in terms of acoustical properties as well. Due to their considerably low sound absorption characteristics, cement- 
based plasters seemed to definitely-destroy the original acoustical features of historical baths' interiors.

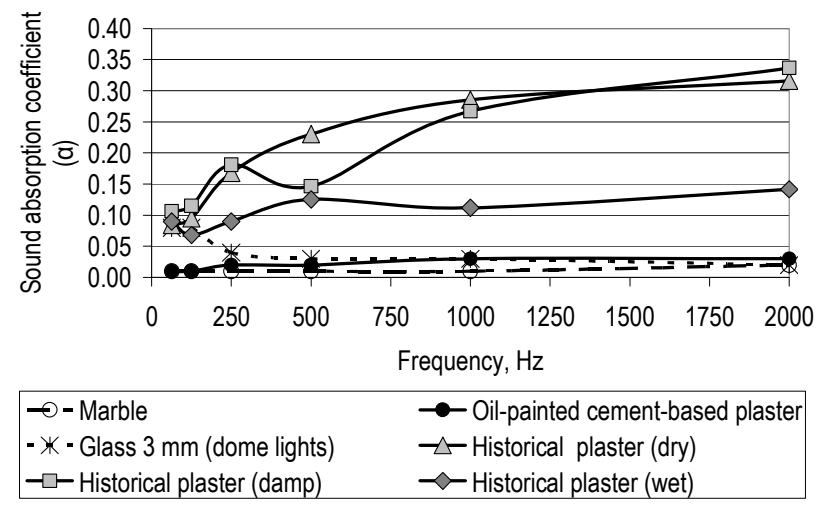

Fig.2 Comparison of sound absorption coefficients of marble, glass, oil painted cement-based plaster and historical lime plaster versus frequency, Hz. The data for marble, glass, oil painted cement-based plaster were taken from the literature $[2,3]$.

\subsection{Original acoustical features of Sengul Hamam}

The original acoustical features of the Sengul Hamam, both for the men's and women's sections, were defined in terms of $R T, E D T, L F 80$, STI and $C 80$ values. The data obtained from the analyses of ORIGINAL case, were evaluated according to the optimum values, given in the literature [2$4,9]$ for a satisfactory speech and musical performances.

The average $R T$ values of the women's section were determined to be $3.2 \mathrm{~s}$ in mid frequency while it was $2.6 \mathrm{~s}$ for the men's section (Table 2). Due to the larger volume of the women's section, its RT was longer than the men's section. These were the results obtained for the unoccupied situation of the interiors. In Fig. 3 , the $R T$ values between $1.5 \mathrm{~s}$ and $2.5 \mathrm{~s}$ shows the optimum range for the speech and musical performances; the $R T$ values between the $2.5 \mathrm{~s}$ and $3.5 \mathrm{~s}$ shows the range for the fuller and richer musical sound while some loss of articulation may be expected in speeches $[4,10]$. When compared with those desirable reverberation times classified by Nave \& Nave [4], both men's and women's sections had $R T$ in acceptable ranges for the purposes of speech and music.

\begin{tabular}{lcccccc}
\hline & \multicolumn{3}{c}{ Women's Section } & \multicolumn{3}{c}{ Men's Section } \\
& \multicolumn{3}{c}{ ORIGINAL Case } & \multicolumn{3}{c}{ ORIGINAL Case } \\
\cline { 2 - 7 } & \multicolumn{3}{c}{ Frequency } & \multicolumn{3}{c}{ Frequency } \\
\cline { 2 - 7 } Acoustical & 500 & 1000 & Average & 500 & 1000 & Average \\
Parameters & $\mathrm{Hz}$ & $\mathrm{Hz}$ & $\mathrm{Hz}$ & $\mathrm{Hz}$ & $\mathrm{Hz}$ & $\mathrm{Hz}$ \\
\hline$R T, \mathrm{~s}$ & 3.8 & 2.6 & 3.2 & 3.8 & 1.4 & 2.6 \\
\hline EDT, s & 3.3 & 2.3 & 2.8 & 3.5 & 1.6 & 2.6 \\
\hline C80, dB & -4.3 & -2.3 & -3.3 & -4 & 0.5 & -1.8 \\
\hline LF80 & 0.270 & 0.265 & 0.268 & 0.305 & 0.317 & 0.311 \\
\hline STI & \multicolumn{3}{c}{0.38} & & & 0.40 \\
\hline Volume, $\mathrm{m}^{3}$ & \multicolumn{3}{c}{713.75} & \multicolumn{5}{c}{508.17} \\
\hline
\end{tabular}

Table 2 The results of $R T, E D T, C 80, L F 80, S T I$ values at $500 \mathrm{~Hz}$ and $1000 \mathrm{~Hz}$ for the women's \& men's sections of Sengul Hamam calculated for the ORIGINAL case in unoccupied conditions, and the averages of those values taken at 500 and $1000 \mathrm{~Hz}$.

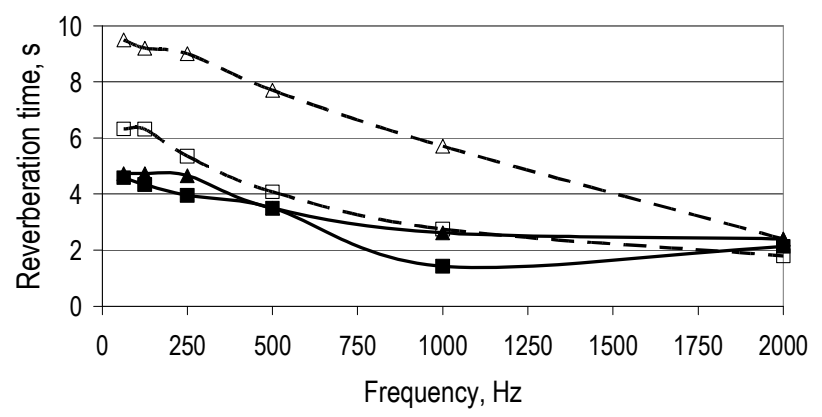

- Men's Section ORIGINAL case $\quad \square$-Men's Section AS-IS case Women's section ORIGINAL case $\rightarrow$ - Women's section AS-IS case

Fig. 3 The $R T$ curves of men's and women's sections of Sengul Hamam, calculated for ORIGINAL and AS-IS cases in unoccupied conditions, versus the frequencies between $63 \mathrm{~Hz}$ and $2000 \mathrm{~Hz}$.

The EDT values were calculated to be almost the same as the $R T$ values, showing that a proper sound diffusion was achieved at the interiors of the structure (Table 2).

The average values of $L F 80$ in mid-frequency were found to be 0.27 to 0.31 for women's and men's sections, respectively (Table 2). Those values fell into the upper limits of acceptable ranges of 0.1 to $0.3 \quad[11,12]$ corresponding to the $L F 80$ values preferable for halls. The higher values of $L F 80$ obtained for Sengul Hamam exhibited that impression of being surrounded or enveloped by sound was strong due to the lateral reflections coming from the marble-clad reflective side walls.

STI is a measure of intelligibility of speech, dependent upon the background noise level, the reverberation time and of the size of the space, and its rating varies from 0 (completely unintelligible) to 1 (perfect intelligibility) [3, 13]. According to the intelligibility rating given in the standards, both the women's and men's sections were found to have poor speech intelligibility with the $S T I$ values of 0.38 and 0.40 , respectively, showing the difficulty in understanding of speech (Table 2). These poor STI values were due to the average $R T$ values of 2.6 and 3.2 determined for the men's and women's sections, respectively, which were above the desirable ranges of $1 \mathrm{~s}$ to $1.5 \mathrm{~s}$ for a good articulation of speech defined in literature [3-5]. The large volume of the domed/vaulted structure and hot and humid microclimatic conditions should have also influenced the STI values, consequently, reduced the intelligibility of speech.

The average $C 80$ values in mid-frequency were found to be $-3.3 \mathrm{~dB}$ and $-1.8 \mathrm{~dB}$ for the women's and men's sections of Sengul Hamam, respectively (Table 2). These values seemed to fall into the acceptable range of $+4 \mathrm{~dB}$ to $-4 \mathrm{~dB}$, providing preferable musical clarity $[3,14]$. It is also wellknown that the $R T$ values above $2.5 \mathrm{~s}$ and the $C 80$ values in betweeen $0 \mathrm{~dB}$ and $-4 \mathrm{~dB}$ designate a richness and fullness of sound [3, 4, 14]. The $R T$ values of Sengul Hamam, being slightly above $2.5 \mathrm{~s}$, together with its $C 80$ values being in the preferable ranges, proved the presence of successful acoustical features in an historical Turkish bath, particularly for musical activities.

According to these results, Sengul Hamam was originally found to have quite well-designed acoustical features in terms of basic acoustical parameters. A conscious use of historical plasters having high sound absorption properties 
also signalled the experience of materials technology achieved in the past.

\subsection{The effect of recent repairs to their acoustical features}

The results obtained from the analyses of $A S-I S$ case were summarized in Table 3 . When compared with the ORIGINAL case, the present situation of the acoustical features after the recent repairs was quite different, especially in terms of $R T, E D T$ and $C 80$. The use of contemporary materials for repairs, such as cement-based plasters, having less sound absorption properties as shown in Fig.2, seemed to destroy the inherently-good acoustical features.

For $A S-I S$ case, the average values of RT in mid-frequency were found to be $5.3 \mathrm{~s}$ and $3.5 \mathrm{~s}$ for the women's and men's section, respectively. The $E D T$ values were also found to be parallel with the $R T$ values. Both $R T$ and $E D T$ values were observed to be considerably longer than those of ORIGINAL case (Fig. 3 and Table 3). Longer RT and EDT values above $3.5 \mathrm{~s}$ exhibited the high degree of sound diffusion and severe loss of articulation in spaces.

The $\mathrm{C} 80$ values in the frequencies of $1 / 1$ octave bands were given in Fig.4 both for the AS-IS and ORIGINAL cases. The $\mathrm{C} 80$ values of the AS-IS case was found to be lower than those of the ORIGINAL case, being lower than $-4 \mathrm{~dB}$. These low C80 values designated the severe loss sound articulation quantitatively (Table 3 and Fig.4).

The STI values of $A S-I S$ case were determined to be the same as the ORIGINAL case, showing a poor intelligibility of speech in the spaces (Table 2 and Table 3 ).

The LF80 values in mid-frequency obtained for the AS-IS case were found to be 0.3 for both women's and men's sections, respectively (Table 3 ). Those values were almost the same as the $L F 80$ values for the ORIGINAL case since marble tiles were used at side walls for both cases. Those values designated that sense of being surrounded by sound were good for $A S$-IS cases. On the other hand, having good $L F 80$ values is not enough for perceiving the sounds in good quality. Due to the long $R T$ and $E D T$ and low $C 80$ and $S T I$ values of the $A S$-IS case, the acoustical ambient in Sengul Hamam exhibited muddy environment with background noise and distracting echoes causing less speech articulation and increase in vocal effort of the speaker.

\begin{tabular}{lcccccc}
\hline & \multicolumn{3}{c}{ Women's Section } & \multicolumn{3}{c}{ Men's Section } \\
& \multicolumn{3}{c}{ AS Is Case } & \multicolumn{3}{c}{ AS IS Case } \\
\cline { 2 - 7 } & \multicolumn{3}{c}{ Frequency } & \multicolumn{3}{c}{ Frequency } \\
\cline { 2 - 7 } Acoustical & 500 & 1000 & Average & 500 & 1000 & Average \\
Parameters & $\mathrm{Hz}$ & $\mathrm{Hz}$ & $\mathrm{Hz}$ & $\mathrm{Hz}$ & $\mathrm{Hz}$ & $\mathrm{Hz}$ \\
\hline T30, s & 5.9 & 4.7 & 5.3 & 4.1 & 2.8 & 3.5 \\
\hline EDT, s & 5.5 & 4.4 & 5.0 & 4.0 & 2.6 & 3.3 \\
\hline $\mathrm{C} 80, \mathrm{~dB}$ & -6.0 & -5.0 & -5.5 & -4.6 & -2.6 & -3.6 \\
\hline LF80 & 0.299 & 0.300 & 0.300 & 0.285 & 0.295 & 0.290 \\
\hline STI & \multicolumn{3}{c}{0.38} & & & 0.40 \\
Volume, $\mathrm{m}^{3}$ & & 713.8 & & 508.2 & \\
\hline
\end{tabular}

Table 3 The results of $R T, E D T, C 80, L F 80, S T I$ values at $500 \mathrm{~Hz}$ and $1000 \mathrm{~Hz}$ for the women's \& men's sections of Sengul Hamam calculated for the $A S$ - $I S$ case in unoccupied conditions, and the averages of those values taken at 500 and $1000 \mathrm{~Hz}$.

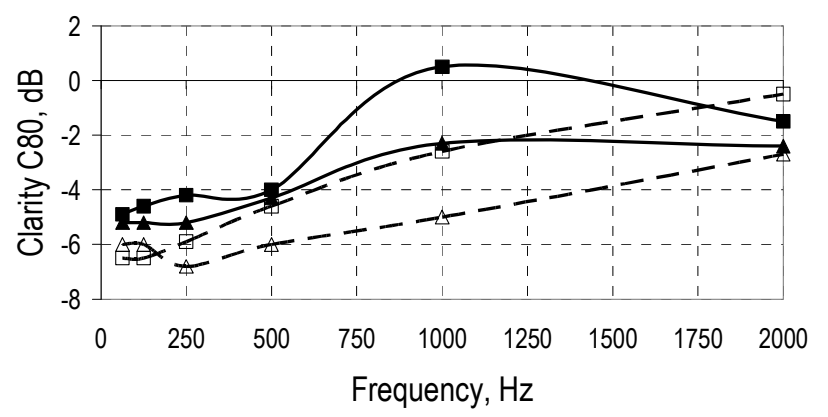

- Men's Section ORIGINAL case $\quad \square$ - Men's Section AS-IS case

-Women's section ORIGINAL case $\rightarrow$ - Women's section AS-IS case

Fig.4 The C80 curves of men's and women's sections of Sengul Hamam, calculated for ORIGINAL and $A S$ - $I S$ cases in unoccupied conditions, versus the frequencies between $63 \mathrm{~Hz}$ and $2000 \mathrm{~Hz}$.

In short, contemporary cement-based plasters were not suitable materials for the repairs of historical Turkish baths due to their incompatible acoustical properties, such as less porosity and less sound absorption coefficient characteristics. The analyses of 3D acoustical simulation proved that the well-designed original acoustical features of Sengul Hamam have been destroyed by recent repairs using such contemporary cement-based plasters.

\section{Conclusion}

The study exhibited that Sengul Hamam had originally well-designed acoustical features providing a desirable musical sound at interiors. This success was particularly due to the conscious use of historical materials. The knowledge on sound absorptive characteristics of historical plasters also revealed the experience of materials technology achieved in the past and established a successful acoustical ambient for historical bath structures.

This study, in fact, helped us to define the acoustical specifications for historical baths which should be fulfilled by restorations.

Further studies are needed to determine the acoustophysical properties of both historical materials and repair materials. The impact of any repair work on original acoustic behaviour of an historical structure can be assessed beforehand in terms of compatible material selection.

\section{Acknowledgement}

The authors thank to Materials Conservation Laboratory (MCL) at the METU Department of Architecture for supply materials throughout the study, to Acoustics Laboratory at METU Department of Mechanical Engineering for the kind assistance during the experimental stage of the study; and to the Vakiflar Genel Mudurlugu (General Pious Foundation) for their permission to use the $1 / 50$-scale measured drawings of historical baths examined in the study. 


\section{References}

[1] ISO 3382:1997 - Acoustics measurement of the reverberation time of rooms with reference to other acoustical parameters, International Organization for Standardization (1997).

[2] M.D. Egan, Architectural Acoustics, Mc-Graw Hill, Inc., New York (1988).

[3] M. Long, Architectural Acoustics, Elsevier Academic press, London (2006)

[4] C.R. Nave, B.C. Nave, Physics for the Health Sciences, 3rd Ed., W. B. Saunders Co (1985).

[5] J. Cowan, Architectural Acoustics Design Guide, McGraw Hill, New York (2000).

[6] A. Kandemir, A. Tavukcuoglu, E. N. Saltik, "In situ assessment of structural timber elements of a historic building by infrared thermography and ultrasonic velocity", Infrared Physics \& Technology, 49, 243-248 (2007).

[7] E.N. Caner, Ş. Demirci, A.G. Türkmenoğlu, "Deterioration of Dolomite by Soluble Salts in Divriği Great Mosque-Turkey", In: G. Felix (Ed.), Vth International Congress on Deterioration and Conservation of Stone, Vol.1, 574 p. Ecole Polytechnique Federale de Lausanne, pp. 299-305 (1985).

[8] E.N. Caner Saltık, "Damage to brickwork by salt crystallization", In: Proceeding of the $4^{\text {th }}$ Expert meeting Berlin, Amersfoort, 25-27 October 1990, pp.51-60. Berlin, Umweltbundesamt (1991)

[9] H. Benade, Fundamentals of Musical Acoustics, Oxford University Press (1976)

[10] W.J. Cavanaugh, J. A. Wilkes, Architectural Acoustics: Principles and Practice, John Wiley \& Sons, Inc., New York, (1999)

[11]M. Barron, "Measured Early Lateral Energy Fractions in Concert Halls and Opera Houses" Journal of Sound and Vibration 232(1), 79-100 (2000).

[12] A.H. Marshall, M. Barron, "Spatial Responsiveness in Concert Halls and the Origins of Spatial Impression" Elsevier Applied Acoustics 62, 91-108 (2001).

[13]H.J.M. Steeneken, "Standardization of Performance Criteria and Assessments Methods for Speech Communication", http://www.steeneken.nl/sti/Standardization_STI_website.pdf, 19 June 2006

[14]L. Beranek, How they sound Concert and Opera Houses, Acoustical Society of America, New York (1996). 